\title{
THE FUNCTIONS OF CLEARLY IN ACADEMIC DISCOURSE: FROM AN ADVERB OF MANNER TO A DISCOURSE MARKER
}

Keywords: clearly, academic discourse, evidential, discourse marker, heteroglossic (dis)engagement

\begin{abstract}
The aim of this paper is to identify and systematize the functions of clearly in academic discourse. The adverb shows a continuum of manner and modal meanings, and signals the existence of reliable evidence for claims, which makes it a useful rhetorical device in research articles. The study is based on a corpus of 80 research articles (ca. 580,000 words) representing three disciplines and three branches of science: linguistics (the humanities), sociology (social sciences) and physics (natural sciences). It shows that clearly is used to involve the reader in the process of data analysis (both manner and modal uses), to summarize the findings, make conclusions (modal uses), and to appeal to shared knowledge (discourse marker). Appeals to shared knowledge are only attested in the subcorpora of linguistics and sociology, which tend to adopt a more interactional style of writing than the natural sciences, while the other functions are found in the research articles of all three disciplines. Using White's (2003) notion of heteroglossic (dis)engagement, clearly can be said to have dialogically contractive functions. Its presence in the text indicates the author's wish to encourage the reader to adopt his/her perspective.
\end{abstract}

\section{Introduction}

Clearly is a multifunctional adverb whose rhetorical properties are frequently exploited in academic discourse. It can be used both as an adverb of manner and, in its modal sense, as a marker of authorial stance, strengthening the author's claims, and engaging in a discussion with the reader. This paper focuses on the use of clearly 
in research articles representing three academic disciplines and, at the same time, three branches of science: linguistics (the humanities), sociology (social sciences) and physics (natural sciences), which have elsewhere been demonstrated to make a relatively frequent use of clearly (Rozumko 2017). Its frequent use in research articles makes it worthwhile to analyze the specific functions it performs in the discourse of the three disciplines. The study is based on a self-compiled corpus of research articles. In the discussion of the discourse functions of clearly, reference is made to White's (2003) notion of heteroglossic (dis)engagement, and in the analysis of its meanings - to the grammaticalization framework.

\section{The properties of clearly: From an adverb of manner to a stance marker}

As already signalled, clearly can be used both as an adverb of manner (to speak/ think clearly) and a modal marker expressing the author's stance (Clearly, they are not treating us seriously). Stance is understood here as "the writer's textual voice" expressing his/her "judgements, opinions and commitments" (Hyland 2007: 92). In its use as a stance marker, clearly is said to express conviction (e.g. Quirk et al. 1985: 621) which "depends on evidence that is either physically perceptible, or a matter of very easy, transparent inference from publicly available evidence" (Ernst 2009: 514). Because of its reliance on evidence it is classified as an evidential adverb (e.g. SimonVandenbergen, Aijmer 2007). Certainty is a notion which is primarily associated with epistemic modality. It needs to be noted that the relation between epistemic modality and evidentiality is a matter of considerable disagreement (see e.g. Portner 2009: 167-172). Some linguists argue that the two notions should be separated, as true evidentials only indicate the source of information, while epistemic markers signal the speaker's evaluation of the truth value of the proposition (e.g. Aikhenvald 2004). Others, however, maintain that "some forms might be both epistemic and evidential" (Nuyts 2001: 57). Because English adverbs referring to the source of information have been reported to always convey "a modal meaning" (Simon-Vandenbergen, Aijmer 2007: 31) and mark the qualified information as certain or uncertain, in this study I adopt the view that in the description of English adverbs the two notions can be treated as complementary. Thus, clearly can be considered as an epistemic marker because it expresses certainty, and as an evidential adverb because it signals that the speaker's certainty is based on external evidence.

In addition to manner and evidential uses, clearly occurs in contexts where it appears to be ambiguous (or intermediate) between its manner and evidential senses (cf. Simon-Vandenbergen, Aijmer 2007: 165), as well as those in which its interactional properties are more pronounced than its reliance on evidence. In other words, it can be said to show different levels of grammaticalization in different contexts. Grammaticalization has been demonstrated to be responsible for the development of adverbs of manner into epistemic adverbs, and, in some cases, subsequently into discourse markers (e.g. Traugott, Dasher 2002), i.e. items which acquire "post-epistemic" meanings (Cornillie, Pietrandrea 2012: 2112) and perform "both a contextualizing and an 
interactional role" (Travis 2006: 219) in discourse. Some linguists (e.g. Erman, Kotsinas 1993) prefer to use the term "pragmaticalization" to refer to the development of discourse functions as the items in question develop new pragmatic functions. The process involves, inter alia, the subjectivization of the adverb, and, in syntactic terms, its movement to the sentence initial position (cf. e.g. Traugott 1995). Subjectivity and objectivity have been discussed extensively by numerous authors. In this study, I adopt Verstraete's (2001: 1506) distinction summarizing subjectivity as "speakerrelated", and objectivity as "content-related function". Another useful notion is that of intersubjectivity, i.e. the speaker's awareness of the addressee (Ädel 2014: 102).

\section{Dialogic functions of modal markers}

Academic discourse is essentially dialogic (cf. Hyland 2005a, 2014; Livnat 2012). It may be seen "as a persuasive endeavour that owes as much to a writer's development of an appropriate relationship with his or her readers as the demonstration of absolute truth, empirical evidence or flawless logic" (Hyland 2014: 1). Modal markers are now increasingly discussed in the context of their dialogic functions (e.g. Martin, Rose 2003), while estimating the truth-value of the proposition, traditionally presented as the central function of epistemic modality, is no longer seen "as the primary motivation" (White 2003: 280) for using them. Epistemic adverbs can thus be viewed as elements of the writer-reader interaction in research articles.

A useful point of reference in discussion of the functions of clearly in academic discourse is White's (2003) notion of "heteroglossic (dis)engagement" (cf. also Martin, White 2005: 134), and categorization of utterances into "dialogically expansive" and "dialogically contractive". A dialogically expansive utterance "entertains dialogically alternative positions and voices", while a dialogically contractive utterance "acts to challenge, fend off or restrict the scope of such" (White 2003: 262). White's category of dialogic expansion is represented by two modes: (1) "entertain": "entertaining alternative positions to that currently being referenced", and (2) "attribute": the speaker attributes "the viewpoint to an external voice" by either acknowledging it or distancing himself/herself from it (White 2003: 274). The category of dialogic contraction comprises the modes of: (1) "disclamation", further subcategorized into "denial" (negation) and "countering" ("concessives, adversatives, counter-expectancy"), and (2) "proclamation", further subdivided into "concurrence" ("the textual voice ... presents itself as aligned with the construed reader, as having the same belief or attitude or knowledge"), "pronouncement” (“intensifications, authorial emphases or explicit authorial interventions and interpolations"), and "endorsement" ("foregrounding of a textual voice ... by introducing some external source into the text attribution") (White 2003: 269). White (2003: 274) also introduces the notion of "justification", which refers to wordings that are used to justify and substantiate propositions, e.g. therefore, for this reason, this is why, which Fryer (2013: 187), in his summary, places in the category of proclamation. Pérez-Llantada Auría (2011) argues that Anglophone scholars show preference for a "heteroglossic disengagement" mode of expression 
in their articles, i.e. they tend to construe their audiences as sharing their beliefs and knowledge. This paper will attempt to identify the roles which clearly plays in the process of readership construal.

\section{The corpus}

The corpus used in the present study comprises 80 research articles (ca. 580,000 words), each of the subcorpora consisting of about 200,000 words. The linguistics and the sociology subcorpora contain 20 articles each; the physics subcorpus contains 40 articles because articles in this area are generally shorter than those in the humanities and social sciences. Most of the articles come from electronic collections of scholarly publications (EBSCO, ScienceDirect). The texts were copied and saved as document files to establish their size using Microsoft Office Word tools. The authors' biographical notes, references, and acknowledgements were disregarded in the word count. The structure of the corpus is summarized in Table 1.

\begin{tabular}{lcc} 
(sub)corpus & $\begin{array}{c}\text { number of } \\
\text { articles }\end{array}$ & $\begin{array}{c}\text { number of } \\
\text { words }\end{array}$ \\
\hline linguistics & 20 & 202,007 \\
sociology & 20 & 185,034 \\
physics & 40 & 191,112 \\
total & 80 & 578,153
\end{tabular}

Table 1. The structure of the corpus

The corpus is relatively small, which made it possible to analyze all the occurrences of clearly individually. As a result of the analysis, its uses in fragments which fall outside the domain of academic discourse, e.g. linguistic examples discussed in the papers, were disregarded in the count. Overall, 149 occurrences of clearly were identified in the corpus. Table 2 shows the number of occurrences of clearly in each of the subcorpora, its frequencies per 200,000 words and per article.

\begin{tabular}{lccc} 
discipline & $\begin{array}{c}\text { number of } \\
\text { occurrences in } \\
\text { the corpus }\end{array}$ & $\begin{array}{c}\text { frequency per } \\
\mathbf{2 0 0 , 0 0 0} \text { words }\end{array}$ & $\begin{array}{c}\text { frequency per } \\
\text { article }\end{array}$ \\
\hline linguistics & 61 & 60.39 & 3.05 \\
sociology & 47 & 50.80 & 2.35 \\
physics & 41 & 43.05 & 1.02 \\
total & 149 & 154.24 & -
\end{tabular}

Table 2. Frequency of clearly in the corpus 
Table 2 shows that clearly is most frequent in the linguistics articles, and the least frequent in the physics subcorpus. It needs to be remembered that the number of articles in the physics subcorpus is twice as high as in the case of linguistics and sociology, so the frequency of clearly per article is the lowest in this subcorpus: 1.02 (as compared to 3.05 in the case of linguistics, and 2.35 in the case of sociology). Natural sciences generally use fewer markers of authorial stance than the humanities and social sciences (cf. Hyland 2005b, 2014), so this result was to be expected. Despite some discipline specific tendencies in academic discourse, individual variation is also considerable (cf. Fløttum et al. 2006), and a bigger corpus, which would level out such differences to a greater extent, could produce different findings. However, the focus in this paper is not on statistical analysis but on the functions of clearly, and the number of occurrences of the adverb it contains seems sufficient for this purpose.

\section{Clearly in the corpus}

\subsection{Clearly as an adverb of manner}

When used as an adverb of manner, clearly means "in a clear manner, esp. in a way that is easy to hear, read or understand" (LDOCE). In the articles I analyzed, it modifies verbs which communicate research results, such as show, link, illustrate, convey, as in examples (1)-(4), and adjectives used in the description of findings, e.g. delineated in (5) and verbal in (6). It is attested in this function in the research articles of all three disciplines.

(1) The data clearly show that the IPS series persists in the presence of organic monolayers and appears to follow the correct asymptotic behaviour. (PHYS 21)

(2) If children are transplanted before they learn their native tongue, they develop their linguistic capacity in the foreign one. This undeniable fact, it might be said, clearly shows that language is the mere reproduction of what is heard, depending entirely on social intercourse without consideration of the unity and diversity of the people involved. (LING 3)

(3) Additionally, future research should attempt to link more clearly the relationship between public opinion and media presentations. (SOCIO 20)

(4) ... relations of temporal sequence can be clearly conveyed in the language. (LING 1)

(5) Experimental studies that have explored the role of backchannels in modulating speakers' moment-by-moment talk have typically done so by having pairs participate in highly structured tasks, involving clearly delineated goals and roles. (LING 9)

(6) Johnston and Schembri (2007) adopt Liddell's analysis but use a slightly different term - depicting signs - to include those constructions which do not always have a clearly verbal function. (LING 2)

Generally speaking, clearly can be used to modify verbs denoting activities which are available for sensory verification, e.g. speak, write (cf. also Simon-Vandenbergen, 
Aijmer 2007: 163), but it can also be used with verbs referring to activities requiring the author's subjective evaluation. (1) and (2), where clearly modifies the verb show, are cases in point. While in both (1) and (2) clearly is used as an adverb of manner, it refers to the author's assessment of what "the data" and "this undeniable fact" show. It has a more judgemental character than in the cases when it modifies such verbs as speak. Determining whether someone is speaking clearly or whether a specific fact shows something clearly requires a different type of judgement. The former involves sensory experience, while the latter is an opinion. In (2), the interpretative sense is emphasized by the hedge "it might be said" which precedes the statement with clearly. There are also uses of clearly which seem to be ambiguous between its manner and modal sense, e.g. (7).

(7) ... to say that someone has one hand clearly implies that one other hand is missing, i.e. unlike as with, say, head or nose. (LING 1)

In (7) clearly may be interpreted as both meaning that the implication is clear and that it is clear to the author that the statement conveys the implication that "the other hand is missing". Such uses involve an interplay of objectivity and subjectivity which is only a step away from the truly modal uses of the adverb.

\subsection{Modal uses of clearly: Involving the reader in the interpretation of the author's data}

Clearly is often used to involve the reader in the author's analysis of his/her data, and to persuade them that the author's interpretation is correct. Such uses are found in the subcorpora of all three disciplines. In such cases, its evidential sense is activated, i.e. clearly signals that the writer's interpretation is based on available evidence. It indicates that the evidence is clear and easily perceptible, thus making it easy for the author to make the claim. As Simon-Vandenbergen and Aijmer (2007:314) put it, by using clearly the author communicates "I am saying this and it can be seen by everyone". Examples of such use are provided in sentences (8)-(11).

(8) Syntactic change has clearly occurred in the above scenario. Note that there is no change in Grammar 1 itself, only in its output, which cannot be attributed to intralinguistic factors. Yet Grammar 2 is different. (LING 10)

(9) In these examples, the contrast is clearly between the NPs in each case. (LING 13)

(10) Compared to the other expressions, it lies roughly in the middle of them up to just above the peak, where it clearly gives the best fit to the measurements, gives the highest values near the dip, lies within their range of values between roughly $50 \mathrm{MeV}$ and $2 \mathrm{GeV}$, and gives the lowest values at higher energies. (PHYS 3)

(11) Emergence, in both "relational" and "strong" forms, is clearly an important implicit concept in Durkheim's writings. (SOCIO 5)

In (8)-(11), clearly refers to the specific instances discussed by the author ("in the above scenario", "in these examples"). The reader is invited to consider them and accept the author's interpretation. Such intersubjective use is well illustrated in (8), 
which additionally contains the expression "note that..." which explicitly addresses the reader. Clearly expresses the writer's view and involves the reader in the process of formulating it. In Fryer's (2013: 188) discussion of (dis)engagement strategies in medical research articles, clearly appears in examples illustrating White's (2003) function of "justification". This function of clearly is also illustrated in my corpus: it provides justification for the author's judgement, and constructs "the textual voice engaged in persuasion and some other communicative participant (typically the immediate addressee) as being in the role of 'persuadee"' (White 2003: 274).

When clearly is used to guide the reader through the data, it commonly appears in the medial position, such as in (8)-(11). These are the instances where, using Quirk et al.'s (1985) terminology, clearly functions as a subjunct, i.e. it has a local scope and qualifies a fragment of a sentence, e.g. an adjective or a noun phrase. It shows a medium level of grammaticalization and subjectivity. By occurring in the immediate neighbourhood of the part it comments on, it "pretends" to be more content- than author-related. The evidence is evaluated while the writer remains in the background. However, initial clearly is also used in the discussion of the data, as in (12) and (13).

(12) Clearly, a cancellation of the terms on the right hand side is required in order to obtain the measured value of mz. (PHYS 8)

(13) Clearly this characteristic is not relevant for sign languages. (LING 2)

In (12) and (13), clearly has a scope over the entire sentence; it is a disjunct in Quirk et al.'s (1985) terms. It is more subjective and has a more judgemental character than in the medial position. A decision to use initial clearly instead of the medial one results in a shift of focus from the content to the author's judgement. The statement becomes more authoritative. Simon-Vandenbergen and Aijmer (2007: 307) link clearly with White's (2003: 269) functionality of "pronouncement": "explicit authorial interventions". It is a strategy of dialogical contraction, i.e. limiting the space for alternative views. Clearly is one of the devices used to minimize space for contrasting views, and to strengthen the speaker's voice.

\subsection{Inferential clearly used to make a conclusion}

In the subcorpora of all three disciplines, clearly is used to summarize a point in a discussion and to make a final conclusion. In such cases, it often appears in the sentence initial position, where, as already mentioned, it is more subjective and more highly grammaticalized than medial clearly. Clearly explicitly signals the writer's opinion, but it also objectivizes it by indicating that it is based on verifiable evidence. In such cases, its meaning is often paraphrasable as 'as I/we have demonstrated'. Examples of such use are provided in (14)-(16).

(14) Clearly, everyone interested in linguistics imposes some restrictions on the evidence. (LING 7) 
(15) Clearly, there are differences between different sets of measurements (individual experiments) that are far greater than the quoted errors. (PHYS 3 )

(16) Clearly more empirical research with CA is needed. (LING 9)

The sentence quoted in (14) appears in the final conclusions of the paper from which it was excerpted, (15) is used to summarize research in a specific area the beginning of the article, while (16) closes one of the sections. Such summarizing uses are characteristic of statements suggesting that more research needs to be done in areas under consideration, such as (16). However, suggestions that further research is necessary are also made using medial clearly, as in (17) and (18).

(17) This is clearly an area in which substantial research is needed. (LING 10)

(18) This is clearly an interesting area for future research. (LING 9)

Initial clearly makes statements suggesting the need for further research sound more final and authoritative. It implies that the author has carefully considered various dimensions of the problem, and presents his/her final voice on the matter. Statements with medial clearly appear to have a more local scope ("this is an interesting area for future research") and a less authoritative character. The suggestion is often made as an aside in the middle of the text, e.g. (17) comes from a footnote. The choice between medial and initial clearly may thus be motivated by the perceived importance of the claim, the scope of the research, as well as the degree of authority which the writer wishes to claim for himself/herself.

\subsection{Clearly as a discourse marker: Appealing to shared knowledge ('as you and I know, as everyone knows')}

Clearly does not always refer to the specific data presented in the paper; in the linguistics and sociology articles it is also used to appeal to general knowledge which the writer assumes to be shared by the addressee (cf. Rozumko 2017). While Simon-Vandenbergen and Aijmer (2007: 306) argue that clearly (unlike obviously) "has not developed the sense of expectation and hence is not a concurrence marker", there are uses of clearly in my corpus which signal that it can also be used to refer to shared knowledge and expectations resulting from that knowledge. Consider examples (19)-(22).

(19) Though prophets and priests remain religious functionaries, clearly sociologists are not priests, who speak for the religious establishment from within it. (SOCIO 4)

(20) ... it is important to recognize socio-natural hybridity, but this should not eclipse awareness of the analytical distinctions between the social and the natural and the variant manner and depth whereby they intertwine. There are, in turn, differing types of socio-natural hybridity ... A cornfield is clearly socio-natural, but so too is a cornfield derived of a genetically modified seed conjured in a laboratory ... (SOCIO 9) 
(21) However, this observation regularly is followed by the claim that rational realism must be wrong because languages clearly depend on humans and hence their nature will be revealed by studying human psychology. (LING 7)

(22) It can be seen from Table 6 that 11 (79\%) of the 14 children with G-SLI failed to reach the above chance criterion for the _wh errors, and none reached the criterion for the _T errors. Of the 3 children (21\%) reaching criterion for wh-trace dependencies, none were close to ceiling, whereas we would clearly expect teenaged individuals to be so. (LING 11)

Examples (19)-(22) make no reference to evidence for the claims. The authors only signal that they think the addressee has the same knowledge - in (19) that sociologists are not priests, in (20) of what a cornfield is, in (21) of the nature of language, and in (22) of the abilities of teenagers - and shares the author's assumptions based on it. By using clearly, the speaker says: 'as you and I know, as everyone knows'. In (22), reference is explicitly made to expectations ("we would clearly expect"), which the author assumes the addressee is likely to share. In such contexts, "the textual voice ... presents itself as aligned with the construed reader" (White 2003: 269), and clearly can be said to function as a marker of concurrence. It becomes a discourse marker appealing to the common ground between the writer and the reader. Its subjective character and dialogic properties are more pronounced in such cases than its evidential sense. The use of clearly as a concurrence marker is not evidenced in the subcorpus of physics research articles, which may be related to the tendency for authorial presence to be less explicitly marked in the natural sciences than in the humanities and social sciences, observed, among others, by Hyland (2005b, 2007, 2014) and Fløttum et al. (2006).

\section{Summary and conclusions}

Academic discourse seems to be well suited for illustrating the continuum of manner and modal meanings of clearly. Clearly is relatively frequent in this type of discourse and is used for a variety of purposes. As an adverb of manner, it is used in data description to persuade the reader that the author's data are solid and can be used to substantiate his/her claims. In its modal use, clearly shows different levels of grammaticalization. When it is used in the medial position and has scope over a part of a sentence, it shows a medium degree of grammaticalization and subjectivity. In such cases, it is used to guide the reader through the process of data interpretation, and encourage them to adopt the author's perspective. It communicates: 'I think this is the case, and I expect you to think the same'. When used in the sentence initial position, it shows a higher level of subjectivity and is used to summarize the findings (in the sense of 'as I have demonstrated') and to suggest areas for future research. Finally, it is also used as a discourse marker, appealing to general knowledge with the aim to establish a common ground between the author and the reader: 'as you and I (and other people) know'. Such appeals to shared knowledge have only been identified in the subcorpora of linguistics and sociology, while the other functions 
have been found in the research articles of all three disciplines. The absence of the uses of clearly to refer to shared knowledge in the physics subcorpus may be seen as an indication of a less explicitly marked authorial presence in the natural sciences than in the humanities and social sciences. Using White's (2003) typology of resources of heteroglossic (dis)engagement, clearly can be said to have dialogically contractive functions; it functions as a marker of pronouncement and justification in the interpretation of the data, and a marker of concurrence when it indicates the expectation that the reader shares the author's knowledge. The findings obtained support Pérez-Llantada Auría's (2011) observation that Anglophone scholars show preference for a "heteroglossic disengagement" mode of expression. Clearly is one of the devices which help authors to construe the audience as sharing their beliefs and knowledge.

\section{References}

Ädel A. 2014. “What I want you to remember is...”: Audience orientation in monologic academic discourse. - Brems L., Ghesquière L., Van de Velde F. (eds.). Intersubjectivity and intersubjectification in grammar and discourse. Theoretical and descriptive advances. Amsterdam, Philadelphia: 101-127.

Aikhenvald A.Y. 2004. Evidentiality. Oxford.

Cornillie B., Pietrandrea P. 2012. Modality at work. Cognitive, interactional and textual functions of modal markers. - Journal of Pragmatics 44.15: 2109-2115.

Erman B., Kotsinas U.-B. 1993. Pragmaticalization: the case of ba' and you know. - Studier i modern språkvetenskap 10: 76-93.

Ernst T. 2009. Speaker-oriented adverbs. - Natural and Linguistic Theory 27.3: 497-544.

Fløttum K., Dahl T., Kinn T. 2006. Academic voices: Across languages and disciplines. Amsterdam, Philadelphia.

Fryer D.L. 2013. Exploring the dialogism of academic discourse: Heteroglossic engagement in medical research articles. - Andersen G., Bech K. (eds.). English corpus linguistics: Variation in time, space and genre. Amsterdam, New York: 183-207.

Hyland K. 2005a. Stance and engagement: A model of interaction in academic discourse. - Discourse Studies 6.2: 173-191.

Hyland K. 2005b. Metadiscourse: Exploring interaction in writing. London.

Hyland K. 2007. Different strokes for different folks: Disciplinary variation in academic writing. - Fløttum K. (ed.). Language and discipline perspectives on academic discourse. Newcastle: 89-108.

Hyland K. 2014. Dialogue, community and persuasion in research writing. - Soler-Monreal C., Gil-Salom L. (eds.). Dialogicity in written specialized genres. Amsterdam, Philadelphia: 1-21. LING s. Appendix.

Livnat Z. 2012. Dialogue, science and academic writing. Amsterdam, Philadelphia.

LDOCE = Longman dictionary of contemporary English. 1987. Harlow.

Martin J.R., Rose. D. 2003. Working with discourse: meaning beyond the clause. New York, London.

Martin J.R., White P.R.R. 2005. The language of evaluation: Appraisal in English. Basingstoke.

Nuyts J. 2001. Epistemic modality, language, and conceptualization: A cognitive-pragmatic perspective. Amsterdam, Philadelphia. 
Pérez-Llantada Auría C. 2011. Heteroglossic (dis)engagement and the construal of the ideal readership. Dialogic spaces in academic texts. - Bhatia V., Sánchez Hernández P., PérezParedes P. (eds.). Researching specialized languages. Amsterdam, Philadelphia: 25-45.

PHYS s. Appendix.

Portner P. 2009. Modality. Oxford.

Quirk R., Svartvik J., Leech G., Greenbaum S. 1985. A comprehensive grammar of the English language. London.

Rozumko A. 2017. Adverbial markers of epistemic modality across disciplinary discourses: A contrastive study of research articles in six disciplines. - Studia Anglica Posnaniensia 52.1: 73-101.

Simon-Vandenbergen A.M., Aijmer K. 2007. The semantic field of modal certainty: A corpusbased study of English adverbs. Berlin, New York.

SOCIO s. Appendix.

Traugott E.C. 1995. Subjectification in grammaticalisation. - Wright S., Stein D. (eds.). Subjectivity and subjectivisation. Cambridge: 31-54.

Traugott E.C., Dasher R.B. 2002. Regularity in semantic change. Cambridge.

Travis C.E. 2006. The natural semantic metalanguage approach to discourse markers. - Fischer K. (ed.). Approaches to discourse particles. Amsterdam: 219-241.

Verstraete J.-Ch. 2001. Subjective and objective modality: Interpersonal and ideational functions in the English modal auxiliary system. - Journal of Pragmatics 33.10: 1505-1528.

White P.R.R. 2003. Beyond modality and hedging: A dialogic view of the language of intersubjective stance. - Text 23.2: 259-284.

\section{Appendix}

The list of journals used to compile the corpus

LING [= Linguistics]: Australian Journal of Linguistics, Journal of Language and Social Psychology, Journal of Pragmatics, Language and Communication, Language and Gender, Language Sciences, Lingua, Linguistics, Text, Topoi.

PHYS [= Physics]: $19^{\text {th }}$ Particles and Nuclei International Conference, AIP Conference Proceedings, Application of Accelerators in Research and Industry, Astroparticle Physics, High Energy Density Physics, Journal of Applied Physics, Journal of Electron Spectroscopy and Related Phenomena, Nuclear Physics, Non-Neutral Plasma Physics VIII, Nuclear Instruments and Methods in Physics Research A, Physica A, Physica B, Physics Essays, Physics Letters, Physics of Fluids, Physics of Plasmas, Powders and Grains, The $8^{\text {th }}$ International Workshop on the Physics of Excited Nucleons, AIP Conference Proceedings, The Journal of Chemical Physics, Unification and Neutrino Physics, Workshop on Dark Matter.

SOCIO [= Sociology]: A Journal of Clinical and Applied Sociology, Canadian Journal of Sociology, Canadian Review of Sociology, Health Sociology Review, Journal of Social Distress and the Homeless, Journal of Sociology, Journal of the History of the Behavioral Sciences, The Forum, Social Forces, Social Indicators Research, Social Science Research, Society, Sociological Forum, Sociological Practice, Sociology of Religion, Studies in East European Thought. 
